\title{
Corrigendum: Frontal hemodynamic responses to high frequency yoga breathing in schizophrenia: a functional near-infrared spectroscopy study
}

\author{
Hemant Bhargav $^{1}{ }^{*}$, H. R. Nagendra ${ }^{1}$, B. N. Gangadhar ${ }^{2}$ and Raghuram Nagarathna' \\ 1 Division of Yoga and Life Sciences, Swami Vivekananda Yoga Anusandhan Samsthana, Bangalore, India \\ ${ }^{2}$ National Institute of Mental Health and Neurosciences, Bangalore, India \\ *Correspondence: urs.aatmiya@gmail.com \\ Edited and reviewed by: \\ Shirley Telles, Patanjali Research Foundation, India
}

Keywords: fNIRS, schizophrenia, yoga, breathing

\section{A corrigendum on}

Frontal hemodynamic responses to high frequency yoga breathing in schizophrenia: a functional near-infrared spectroscopy study

by Bhargav H, Nagendra HR, Gangadhar $B N$ and Nagarathna R (2014). Front. Psychiatry 5:29. doi:10.3389/fpsyt.2014.00029

\section{AUTHOR'S DESCRIPTION OF ERROR AND CORRECTION}

The title of Figure 4 was written as "Frontal hemodynamic responses in schizophrenia patients before (pre), during, and after (post) KB through all the 16 voxels," which is incorrect and should be replaced with "Frontal hemodynamic responses in healthy controls before (pre), during, and after (post) KB through all the 16 voxels."

Conflict of Interest Statement: The authors declare that the research was conducted in the absence of any commercial or financial relationships that could be construed as a potential conflict of interest.

Received: 23 April 2014; accepted: 05 May 2014; published online: 20 May 2014.

Citation: Bhargav H, Nagendra HR, Gangadhar BN and Nagarathna $R$ (2014) Corrigendum: Frontal hemodynamic responses to high frequency yoga breathing in schizophrenia: a functional near-infrared spectroscopy study. Front. Psychiatry 5:55. doi:10.3389/fpsyt.2014. 00055

This article was submitted to Affective Disorders and Psychosomatic Research, a section of the journal Frontiers in Psychiatry.

Copyright (C) 2014 Bhargav, Nagendra, Gangadhar and Nagarathna. This is an open-access article distributed under the terms of the Creative Commons Attribution License (CC BY). The use, distribution or reproduction in other forums is permitted, provided the original author(s) or licensor are credited and that the original publication in this journal is cited, in accordance with accepted academic practice. No use, distribution or reproduction is permitted which does not comply with these terms.
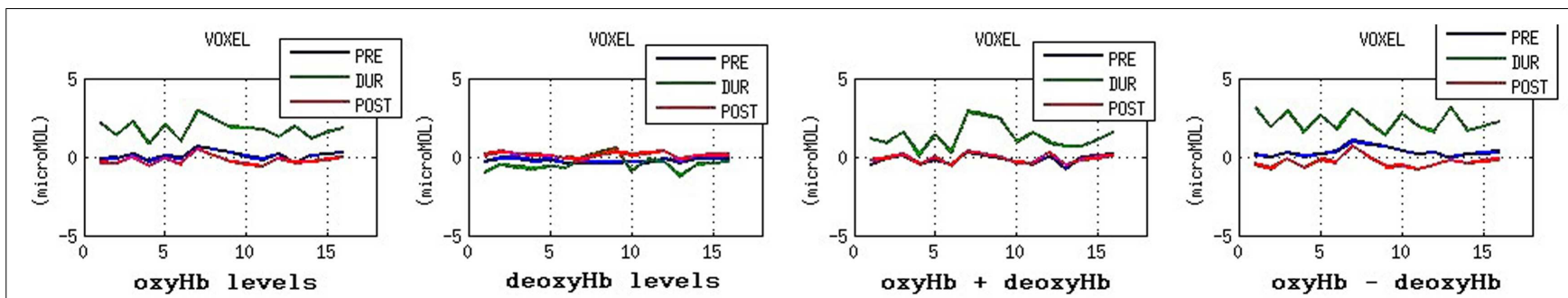

FIGURE 4 | Frontal hemodynamic responses in healthy controls before (pre), during, and after (post) KB through all the 16 voxels. 